\title{
Effects of the Rome IV Criteria to Functional Dyspepsia Symptoms in Saudi Arabia: Epidemiology and Clinical Practice
}

\author{
Georgios Zacharakis ${ }^{1,2}$, Sameer Al-Ghamdi ${ }^{3}$, Jamaan AlZahrani ${ }^{3}$, Abdulaziz Almasoud ${ }^{4}$, \\ Omar Arahmane ${ }^{5}$, Abdullah AIShehri ${ }^{6}$, Moaz Hassan Alharbi ${ }^{7}$, Manal Mahmood Alsalmi ${ }^{8}$, \\ Sultan Bander Alotibi ${ }^{8}$, Yasameen Abdullah Algaradi ${ }^{1}$, Fatimah Nassir Alsadiq ${ }^{9}$ and \\ Pavlos Nikolaidis ${ }^{10}$
}

Endoscopy Unit, Department of Internal Medicine, Prince Sattam bin Abdulaziz University Hospital, College of Medicine, Prince Sattam bin Abdulaziz University ${ }^{1}$, Al Kharj, Saudi Arabia; Endoscopy Unit, Department of Internal Medicine, Limassol General Hospital, St George's Medical School, University of Nicosia ${ }^{2}$, Nicosia, Republic of Cyprus; Department of Family Medicine, College of Medicine, Prince Sattam bin Abulaziz University $^{3}$, Al Kharj, Saudi Arabia; Endoscopy Unit, Prince Sultan Military Medical City ${ }^{4}$, Riyadh, Saudi Arabia; Endoscopy Unit, King Khaled Hospital and Prince Sultan Center for Health Care ${ }^{5}$, Al Kharj, Saudi Arabia; Department of Family Medicine, AlKharj Military Hospital ${ }^{6}$, Al Kharj, Saudi Arabia; Department of Internal Medicine, Security Forces Hospital ${ }^{7}$, Riyadh, Saudi Arabia; Ibn Sina National College for Medical Studies ${ }^{8}$, Jeddah, Saudi Arabia; Almaarefa Medical College ${ }^{9}$, Riyadh, Saudi Arabia; College of Computer and Information Sciences, Al-Imam Mohammad Ibn Saud Islamic University ${ }^{10}$, Riyadh, Saudi Arabia

Background/Aims: Limited data is available in Saudi Arabia (SA) regarding the prevalence of functional dyspepsia (FD) symptoms and its subtypes, as defined by the ROME IV criteria. This study evaluated the burden of self-reported FD symptoms in the adult general population of SA and the current clinical practices.

Methods: A web-based national cross-sectional health survey of the general population of SA was conducted using the Rome IV Diagnostic Questionnaire for Functional Gastrointestinal Disorders in Adults with additional questions on the presence of symptoms compatible with functional heartburn $(\mathrm{FH})$ and irritable bowel syndrome (IBS). The quality of life and somatization questionnaires were also included.

Results: Overall, 3,114 adults completed the questionnaire, but 303 (9.7\%) were excluded due to inconsistent responses. Of the 2,811 consistent responders, 532 (18.3\%) fulfilled the Rome IV criteria for FD symptoms. These were distributed into the FD subtypes as follows: 208 (7.4\%) had postprandial distress syndrome, 228 (8.1\%) had epigastric pain syndrome, and 96 (3.4\%) had the overlapping variant. IBS-like symptoms were reported in 232 (44\%) and FH in 102 (19\%) 19\% (102) of the subjects with functional dyspepsia. H. pylori-associated dyspepsia was reported by $25 \%(87 / 348)$. High somatization, lower quality of life scores, younger age, and female sex were associated more with the FD symptoms participants than those without. Approximately $1 / 5$ respondents used over-the-counter medications to relieve the FD symptoms.

Conclusions: In this population-based survey, FD affected almost $1 / 5$ of the responding adult population in SA, which was less than previously reported. (Korean J Gastroenterol 2020;76:304-313)

Key Words: Dyspepsia; Diagnosis; Prevalence; Irritable bowel syndrome; Heartburn

Received July 31, 2020. Revised October 25, 2020. Accepted October 28, 2020.

(C) This is an open access article distributed under the terms of the Creative Commons Attribution Non-Commercial License (http://creativecommons.org/licenses/ by-nc/4.0) which permits unrestricted non-commercial use, distribution, and reproduction in any medium, provided the original work is properly cited. Copyright (c) 2020. Korean Society of Gastroenterology.

Correspondence to: Georgios Zacharakis, Head of Endoscopy Unit, Department of Internal Medicine, Prince Sattam bin Abdulaziz University Hospital, College of Medicine, Prince Sattam bin Abdulaziz University, Prince Sattam bin Abdulaziz road, Ar Rayyan, Al-Kharj 16277, Saudi Arabia. Tel: +966115886750, E-mail: g.zacharakis@psau.edu.sa, ORCID: https://orcid.org/0000-0002-2859-9188

Financial support: This project was supported by Prince Sattam bin Abdulaziz University, Deanship of Scientific Research, College of Medicine.

Conflict of interest: None. 


\section{INTRODUCTION}

Functional dyspepsia (FD) causes various relatively non-specific symptoms from the upper gastrointestinal (Gl) tract; hence, it is underdiagnosed and undermanaged. ${ }^{1}$ The pathophysiological mechanisms underlying these symptoms are unclear. On the other hand, many associations have been made with gastric motility disorders ${ }^{2}$ and with visceral hypersensitivity. ${ }^{3}$ Furthermore, Helicobacter pylori (H. pylori) infections induce gastric inflammation and lowers the pain threshold for gastric distension. ${ }^{4}$ Other causes include altered gut microbiome, ${ }^{5}$ duodenal inflammation, ${ }^{6}$ and psychosocial dysfunction. ${ }^{7,8}$ Finally, regarding diagnosis, there is no validated biomarker for a diagnosis of FD. The capsaicin test has shown low diagnostic accuracy in clinical practice because of overlap with other upper gastrointestinal disorders, such as gastroesophageal reflux disease. ${ }^{9}$

The Rome IV criteria show improved specificity for functional dyspepsia (FD). ${ }^{10-13}$ The major symptoms of FD include "bothersome" postprandial fullness, epigastric pain, epigastric burning, and early satiation. In addition, the sensation of nausea (but no vomiting) may increase after meals. An FD diagnosis requires that the symptoms be present for at least 3 days per week for 3 continuous months with an onset at least 6 months before the diagnosis. FD can be classified into two subtypes: postprandial distress syndrome (PDS), which involves postprandial fullness and or early satiety; and epigastric pain syndrome (EPS), which is defined as epigastric pain and or stomach burning that is not exclusively postprandial and interferes with typical physical activity. ${ }^{8}$ The various phenotypes of FD and the evolution of ROME criteria from I to IV explain why the prevalence of dyspepsia varies considerably between different populations. Several studies from the past using the Rome I to IV criteria reported a wide range of dyspepsia frequencies. This was attributed to sampling heterogeneity with marked differences in sample size, symptom duration, and methodology used for symptom data collection. ${ }^{14}$ Worldwide, FD affects $21 \%$ of the general population. The prevalence varies from $5 \%$ to $29.5 \%$ because of the use of several old definitions, such as upper gastrointestinal symptoms, but the incidence of FD drops dramatically to $7.6 \%$ with Rome III criteria. ${ }^{14}$

The prevalence of FD in Saudi Arabia, however, is not well characterized. Different definitions have been used in many population studies. Most of these referred to $H$. pylori-associated dyspepsia. This likely contributes to the epidemiological differences described in several of these studies. The prevalence ranges from $38.5 \%$ in the Al Kharj province of central SA, ${ }^{15}$ $46.5 \%$ in Jazzan province, ${ }^{16} 66.1 \%$ in Taif, ${ }^{17} 60.1 \%$ in Gizan ${ }^{18}$ to $86 \%$ in Abha, a southern province of Saudi Arabia. ${ }^{19}$

In this study, using the Rome IV Criteria for functional Gl disorders, this study estimated the prevalence of self-reported symptoms consistent with FD among adults in the general population of SA, to investigate the patient demographics related to these symptoms and better inform current clinical practices.

\section{SUBJECTS AND METHODS}

\section{Study design}

This population study collected and analyzed self-reported data provided by the general population of SA using a web-based cross-sectional health survey adapted from the Rome IV Diagnostic Questionnaire for Functional Gastrointestinal Disorders in Adults ${ }^{10-13}$ to assess the prevalence of FD symptoms. ${ }^{10-13}$ Somatization $^{20}$ and QoL and current clinical practices $^{21,22}$ (e.g., referral for endoscopy, prescribed treatments, and international guidelines) were also assessed. This study was carried out from May 2017 to February 2019.

\section{Ethical considerations}

The study was conducted according to the strengthening the reporting of observational studies in epidemiology statement and by adopting an anonymous self-administered questionnaire to the investigators. The Institutional Ethics Committee of the College of Medicine of the Prince Sattam bin Abdulaziz University of $\mathrm{Al}$ Kharj approved the study (approval no. PSAU/COM/RC/IRB/A/1).

\section{Study participants}

The study targeted a nationally representative sample of adults in SA, 18 years or older, with social media accounts (e.g., Twitter). The volunteers were invited to complete a health survey. Upon agreement, the volunteers received access to an online questionnaire on their upper gastrointestinal symptoms without knowing the purpose of the survey to minimize bias. Responders who failed to complete two attention-test questions correctly or provided conflicting responses on three gastrointestinal inquiries introduced twice in the study for this 
purpose were excluded.

\section{Survey methodology}

A cross-sectional health survey was conducted on adults of the general population of SA. A quota-based sampling approach was applied to collate the demographically balanced and population-representative samples best. To eliminate poor quality reporting based on incomplete data, all missing answers were highlighted by the software and required com- pletion before proceeding to the next question.

A web-based, anonymous, novel questionnaire was administered using a survey program. The questionnaire included symptoms with functional heartburn (FH) and irritable bowel syndrome (IBS) because these often overlap with FD. ${ }^{13}$ A supplementary questionnaire was included to assess the QoL, ${ }^{23}$ somatization, ${ }^{20}$ and factors potentially associated with FD, such as demographic characteristics, treatment, Gl diseases (referral for upper Gl endoscopy), and dietary habits.

Table 1. Characteristics of the Study Population with and without Functional Dyspepsia Symptoms according to Rome IV Diagnostic Criteria (Univariate Analysis)

\begin{tabular}{|c|c|c|c|}
\hline & Non-dyspeptics patients & Dyspeptic patients & $\mathrm{p}$-value \\
\hline \multicolumn{4}{|l|}{ Gender } \\
\hline Female & $1,162(51)$ & $325(61)$ & $<0.001$ \\
\hline Age (years) & $24(18-58)$ & $27(18-58)$ & $<0.001$ \\
\hline $19-29$ & $1,412(62)$ & $192(60)$ & $>0.05$ \\
\hline $30-39$ & $524(23)$ & $138(26)$ & $>0.05$ \\
\hline $40-58$ & $342(15)$ & $74(14)$ & $>0.05$ \\
\hline \multicolumn{4}{|l|}{ Educational level } \\
\hline University & $1,523(67)$ & $340(64)$ & $>0.05$ \\
\hline Secondary school & $410(18)$ & $123(23)$ & $>0.05$ \\
\hline Primary school & $342(15)$ & $69(13)$ & $>0.05$ \\
\hline \multicolumn{4}{|l|}{ Marital status } \\
\hline Single & $1,390(61)$ & 314 (59) & $>0.05$ \\
\hline Married & $820(36)$ & $197(37)$ & $>0.05$ \\
\hline Divorce & $68(3)$ & $21(4)$ & $>0.05$ \\
\hline Widowed & $114(0.5)$ & $5(1)$ & $>0.05$ \\
\hline \multicolumn{4}{|l|}{ Employment status } \\
\hline Employed & $980(38)$ & $218(41)$ & $>0.05$ \\
\hline Self-employed & $137(6)$ & $37(7)$ & $>0.05$ \\
\hline Housewife & $274(12)$ & $49(11)$ & $>0.05$ \\
\hline Unemployed & $296(13)$ & $79(15)$ & $>0.05$ \\
\hline Student & 775 (34) & $164(31)$ & $>0.05$ \\
\hline \multicolumn{4}{|l|}{ Somatic symptom severity scores } \\
\hline PHQ-12 somatization scores & $4.2(3.8)$ & $9.2(5.3)$ & $<0.0001$ \\
\hline Number of somatic symptoms & $3.6(2.9)$ & $6.8(4.1)$ & $<0.0001$ \\
\hline \multicolumn{4}{|l|}{ Short form-8 quality score } \\
\hline Physical component score & $46.6(12.3)$ & $41.2(14.1)$ & $<0.0001$ \\
\hline Mental component score & $41.2(13.1)$ & $39.2(15.7)$ & $<0.0001$ \\
\hline \multicolumn{4}{|l|}{ Smoking } \\
\hline Never & $1,664(73)$ & $378(71)$ & $>0.05$ \\
\hline Yes & $615(27)$ & $154(29)$ & $>0.05$ \\
\hline \multicolumn{4}{|l|}{ Overlapping FGIDs } \\
\hline Irritable bowel syndrome & $205(9)$ & $232(44)$ & $<0.0001$ \\
\hline Functional heartburn & $46(2)$ & 101(19) & $<0.0001$ \\
\hline \multicolumn{4}{|l|}{ Nutritional status } \\
\hline Malnourished & $160(7)$ & $48(9)$ & $>0.05$ \\
\hline Normal & $729(32)$ & $181(34)$ & $>0.05$ \\
\hline Overweight & $593(26)$ & $815(29)$ & $>0.05$ \\
\hline Obese & $615(27)$ & $149(28)$ & $>0.05$ \\
\hline Physical activity at least once weekly & $365(16)$ & 75 (14) & $>0.05$ \\
\hline
\end{tabular}

Values are presented as $\mathrm{n}(\%)$ or median (interquartile range).

PHQ, patient health questionaire-12 somatic symptom scale; FGIDs, functional gastrointestinal disorders. 
The English form of the questionnaire was translated into Arabic by four independent dual-language (Arabic and English) translators and validated as published for the Rome IV Diagnostic Questionnaire for Adults. ${ }^{13}$

The demographic data collected included questions on the following: age; sex; nationality and origin (geographical regions of Saudi Arabia: north, south, west, east, and central); marital status; education level; smoking status; BMI, including weight and height; employment status and physical activity level. This study used quota-based sampling, a multi-stage stratified sampling method with the following strata: I) gender-specific stratum, II) age-specific stratum, and III) level of education stratum.

Moreover, the participants were asked to report any healthcare visits, organic GI disease (e.g., peptic ulcer disease, gastritis, $H$. pylori infection, celiac disease, gastrointestinal tumor, diverticulitis, and inflammatory bowel disease). Furthermore, the subjects were asked to disclose any medicines taken weekly for Gl-related diseases (e.g., antiemetic, antacids, antispasmodics, analgesics, laxatives, and anti-diarrhea agents, either recommended by a doctor or taken over-the-counter [OTC]). The use of supplementary medication (e.g., herbal remedies and traditional Chinese medicine) and psychotropics (e.g., anxiolytics and antidepressants) were also queried. The dietary changes associated with FD therapy were also included. Finally, the participants were asked to provide a general medical history (comorbidities) and abdominal surgical history, including cholecystectomy, appendectomy, bowel resection, hysterectomy, or any other abdominal surgery.

\section{Sample size}

The sample size was calculated using the following equa- tion (OpenEpi, 2016). The sample size required was determined to be 1,083 , with a confidence level of $99.9 \%$. To compensate for any possible data loss, the total sample should exceed this value. Of the 3,120 adult individuals who visited the survey site, 1,760 (56.4\%) agreed to participate in the study.

\section{Statistics analysis}

All statistical analyses were performed using SPSS version 21.0 (IBM Co., Armonk, NY, USA) and have been described elsewhere. $^{24}$

\section{RESULTS}

This study recorded 3,114 potential survey responders who visited the Prince Sattam bin Abdulaziz University Hospital site. Of them, 303 (9.7\%) were inconsistent responders and subsequently excluded from the analysis. Of the residual 2,811 participants, 2,279 (81.1\%) had no symptoms of dyspepsia based on the Rome IV FD criteria and were classified as controls. The remaining 532 participants (18.9\%) fulfilled the criteria for FD symptoms based on the Rome IV diagnostic questionnaire. Responders without and with the Rome IV FD symptoms showed no significant difference ( $p>0.05)$ among the regions of SA (Table 1). The average respondent age for individuals with and without FD symptoms was 27 (18-58) and $24(18-58)$ years old, respectively $(p<0.0001)$ (Table 1). Slightly more than half of the study population (control group) were women (51\%). Moreover, women were significantly more prevalent among the survey participants with FD symptoms (61\%) $(p<0.0001)$ (Table 1). The control participants without FD symptoms were similar to those with FD symptoms in terms

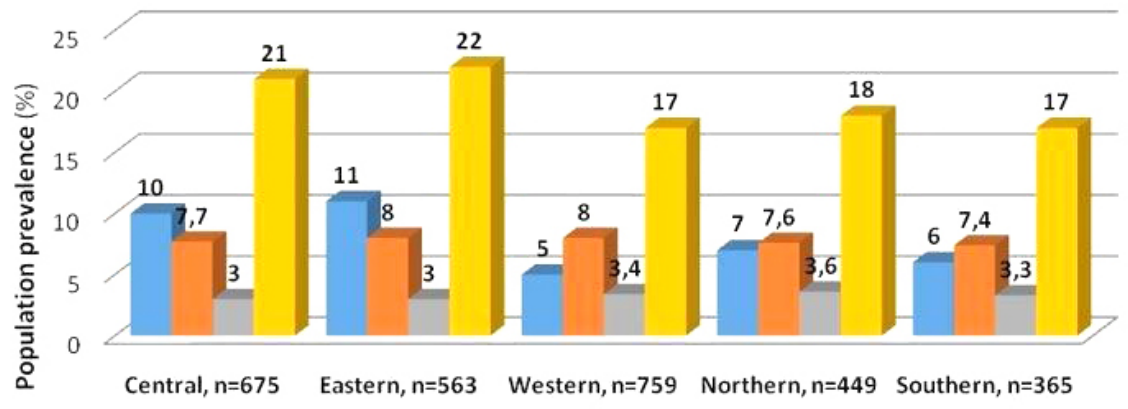

\#PS, $\mathrm{p}=0.01 \approx \mathrm{EPS}, \mathrm{p}=>0.05 \approx$ Overlapping, $\mathrm{p}=>0.05 \approx$ Overall, $\mathrm{p}=0.001$

Fig. 1. Prevalence of functional dyspepsia subtypes based on Rome IV diagnostic criteria between the regions of Saudi Arabia. The p values are between the geographic regions across the country. PDS, postprandial distress syndrome; EPS, epigastric pain syndrome. 
of smoking habit, marital status, employment, education level, nutritional status, and physical activity $(p>0.05)$ (Table 1).

Regarding comorbidities, the participants reported whether they suffered from diabetes mellitus (14\%), hypertension (4\%), thyroid disorder (4\%), heart disease (1\%), headache (25\%), and anemia (13\%). The most common non-Gl symptom was headache (25\%). The Gl-specific conditions/diseases included hemorrhoids (16\%), IBS (17\%), anorexia/bulimia (29\%), diverticulosis (0.5\%) and cholecystitis (34\%).

Regarding the participants with FD symptoms, 532 (18.9\%) out of 2,811 total responders fulfilled the Rome IV criteria for FD. These subjects were distributed equally between the two major FD subtypes: 222 (7.9\%) had PDS; 219 (7.8\%) had EP; 91 (3.3\%) had the PDS-EPS overlapping variant. The Rome IV FD symptoms were more frequent and significantly different in the central and eastern parts of SA ( $n=139 / 675$ [21\%] and $n=124 / 563$ [22\%]) than in the rest western $(n=127 / 759$ [17\%]), northern $(n=80 / 449$ [18\%]) and southern $(n=62 / 365$ [17\%]) regions $(p<0.001)$. In addition, the central and eastern region of Saudi Arabia had more frequent self-reports of PDS (67 [10\%]) and (62 [11\%]) than the western (40 [5\%]), northern (30 [7\%]) and southern (22 [6\%]) regions ( $p=0.001)$, (Fig. 1). The frequencies of the EPS and the overlapping variant were distributed equally across all regions of $S A(p<0.05)$ (Fig. 1).

Fig. 2 shows the distribution of FD subtypes in participant dyspeptic patients according to the Rome IV diagnostic criteria between regions across the country. The most common subtypes were PDS, followed by EPS, but the frequency was not significantly different. The overlapping variant frequency was significantly less common than the other subtypes of FD $(p=0.001)$.
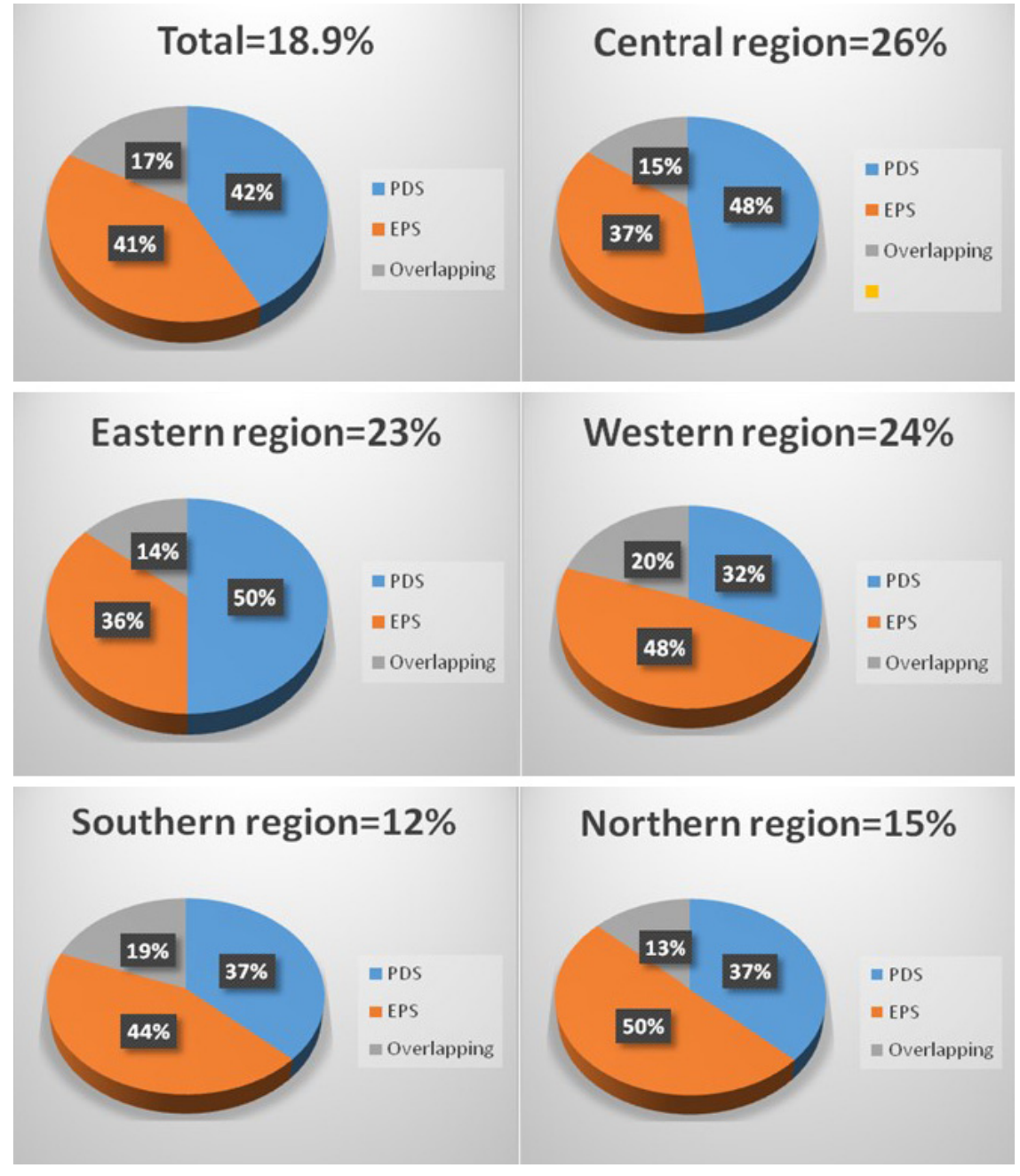

Fig. 2. Distribution of FD subtypes in participant dyspeptic patients according to Rome IV diagnostic criteria between regions across the country. FD, functional dyspepsia; PDS, postprandial distress syndrome; EPS, epigastric pain syndrome. 
IBS and FH were significantly more common in the FD group than in the control group (Table 2). Among the 532 subjects in the FD group, IBS-like symptoms were reported by $44 \%$ (232), FH by $19 \%$ (102), belching by $8.7 \%$ (46), and nausea by $3.1 \%$ (17). IBS was significantly more common in the overlapping PDS-EPS variant group $(86 \%, 78 / 91)$ than

Table 2. Healthcare Usage and Therapies Used Either for Rome IV Functional Dyspepsia Symptoms or Any Other Symptoms (Univariate Analysis)

\begin{tabular}{|c|c|c|c|}
\hline & Non-dyspeptics patients & Dyspeptic patients & p-value \\
\hline \multicolumn{4}{|l|}{ Health care usage } \\
\hline Seen doctor for gastrointestinal disease & $251(11)$ & $138(26)$ & $<0.00001$ \\
\hline Health care visits at least once yearly & $547(24)$ & $223(42)$ & $<0.00001$ \\
\hline \multicolumn{4}{|l|}{ Therapies } \\
\hline \multicolumn{4}{|l|}{ Medication } \\
\hline Prescribed by physician & $433(19)$ & $191(36)$ & $<0.00001$ \\
\hline Over the counter & $387(17)$ & $128(24)$ & $<0.00001$ \\
\hline Not used any drug & $1,459(64)$ & $213(40)$ & $<0.00001$ \\
\hline \multicolumn{4}{|l|}{ Other therapies } \\
\hline Herbal medicines & $205(9)$ & $89(16)$ & $<0.00001$ \\
\hline \multicolumn{4}{|l|}{ Dietary changes or restrictions } \\
\hline Weight loss & $182(8)$ & $101(19)$ & $<0.00001$ \\
\hline Dietary changes $^{a}$ & $410(16)$ & $154(29)$ & $<0.00001$ \\
\hline Avoid smoking & $46(2)$ & $37(7)$ & $<0.00001$ \\
\hline \multicolumn{4}{|l|}{ Medicines taken at least for a week } \\
\hline Antiemetic & $23(1)$ & $32(6)$ & $<0.00001$ \\
\hline Prokinetic & $68(3)$ & $90(17)$ & $<0.00001$ \\
\hline Acid suppressive medicines & $274(12)$ & $196(37)$ & $<0.00001$ \\
\hline Antidepressants & $91(4)$ & $48(9)$ & $<0.00001$ \\
\hline Anti-anxiety drugs & $23(1)$ & $16(3)$ & $<0.0001$ \\
\hline Other therapies (psychotropics, psychotherapy) & $46(2)$ & $32(6)$ & $<0.00001$ \\
\hline Analgesics & $524(23)$ & $223(42)$ & $<0.0001$ \\
\hline Antibiotics for $H$. pylori eradication & $319(14)$ & $348(65)$ & $<0.00001$ \\
\hline
\end{tabular}

Values are presented as $\mathrm{n}(\%)$.

H. pylori, Helicobacter pylori.

${ }^{a}$ Dietary changes included: avoid spice food, avoid heavy meal before sleep, avoid citrus fruits or coffee.

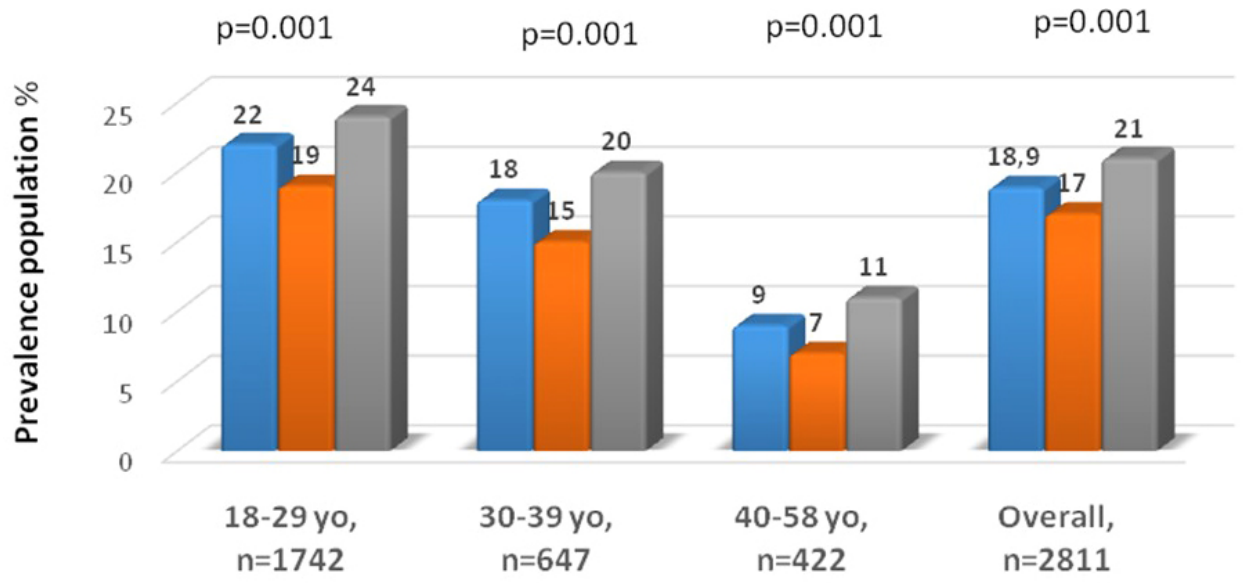

$\square$ Total, $\mathrm{n}=\mathbf{5 3 2} \square$ Male, $\mathrm{n}=\mathbf{2 4 8} \square$ Female, $\mathrm{n}=\mathbf{2 8 4}$

Fig. 3. Prevalence of functional dyspepsia symptoms based on Rome IV diagnostic criteria according to age and gender. 
in those with EPS $(44 \%, 97 / 222)$ or PDS $(26 \%, 57 / 219)$ alone $(p<0.05)$. Similarly, FH was also reported significantly more frequently in the overlapping PDS-EPS variant group (36\%, $33 / 91)$ than in the EPS $(19 \%, 41 / 222)$ and PDS $(13 \%$, $28 / 219)$ groups $(p<0.05)$. The respondents with FD symptoms were more likely to have higher PHQ-12 somatization and lower QoL scores than the control participants without FD symptoms and those with the overlapping PDS-EPS variant (Table 2). H. pylori-associated dyspepsia was reported in $87 / 348$ H. pylori-positive patients (25\%) with sustained symptom resolution after 6 months.

Significant age- and sex-based differences in FD symptoms were identified by comparing the survey responders with FD symptoms with non-FD controls (Table 1). The frequency of FD was significantly higher in the 18-29 years age group $(n=381 / 1,742,22 \%)$ than among those 30-39 years of age $(n=113 / 647,18 \%)$ and $40-58$ years of age $(n=38 / 422,9 \%)$ (Fig. 3). Moreover, FD symptoms were associated with sex but not with the education level or relationship status. Female survey responders reported having FD symptoms more frequently than their male counterparts across all age groups (Fig. 3). Finally, there were no significant differences in age, sex, education level, or relationship status between the FD subgroups.

Regarding the management of FD symptoms, most dyspeptic participants $(58.4 \%)$ reported not using any medication to manage FD symptoms. On the other hand, $22.1 \%$ took prescribed medications, while $19.5 \%$ took OTC medicine. Moreover, $22.6 \%$ of participants who used OTC regimens reported also using herbs to manage their FD symptoms. Those with FD symptoms reported more health care use. These participants also took more medicines and had a lower QoL and higher somatization than those without FD symptoms $(p=0.0001)$ (Table 2). The participants also reported making lifestyle modifications to manage their FD symptoms. In particular, dietary changes, weight loss, and smoking cessation were significantly different compared to the non-dyspeptic control group (Table 2). Responders with FD, who underwent upper gastrointestinal endoscopy (23\%), reported peptic ulcer (2\%), erosive gastritis (9.8\%), and gastritis (22.8\%). A normal mucosa was noted in the remaining cases.

\section{DISCUSSION}

This survey provides the first description of the prevalence of FD symptoms and its subtypes using the Rome IV diagnostic criteria in SA. The prevalence of FD was 19\%, and the FD subtypes were EPS 43\%, PDS 39\%, and overlapping variant $18 \%$. FD symptoms were more common in the younger age group than the older age group and among women than men. Aziz et al. ${ }^{24}$ reported that PDS was the most frequent subtype of FD, representing approximately $60 \%$ of the cases in America, Canada, and the UK. Furthermore, the overall prevalence of FD in these countries was $9 \%$. Other studies also found the PDS variant to be the most prevalent in the general population and the overlapping variant to predominate in hospital settings. ${ }^{25-29}$ These differences could reflect the different genetic, cultural, socioeconomic, dietary, and environmental factors between the different countries.

More than half the respondents with FD symptoms according to the Rome IV criteria resided in the central and eastern regions of the SA, while less than one-fifth were from each of the remaining geographical regions. In addition, the central and eastern regions of Saudi Arabia had a significantly higher frequency of the PDS subtype (11\%) than the other regions (western - 5\%, northern - 6\%, and southern - 6\%). The other two subtypes were similarly distributed across the geographic regions.

This survey showed that responders with FD symptoms had more healthcare use than the non-dyspeptic controls. Only $42 \%$ of the participants sought healthcare resources, and $22 \%$ received treatment (mostly proton pump inhibitors and prokinetics that are not effective for all subtypes). Dyspeptic patients are usually misdiagnosed with gastroesophageal reflux disease, with only $12.5 \%$ receiving an initial FD diagnosis. ${ }^{30}$ In this study, $58 \%$ of respondents did not seek additional healthcare nor receive targeted medications. Of the FD subtypes, the overlapping EPS-PDS variant reported the most healthcare use, the most frequent use of dyspepsia-relevant medications, the highest frequency of overlapping symptoms (e.g., those associated with FH and IBS), the lowest QoL, and the most severe somatization. Overall, the survey specifically tailored for use in the present study effectively revealed differences between the subtypes of FD. On the other hand, there are conflicting data in the literature regarding somatization in FD; some studies report no difference in somatization 
between subtypes, ${ }^{29}$ whereas others reported significant differences similar to the present results. ${ }^{24,25}$

Regarding medications, the use of antidepressants for PDS is not a treatment option in Saudi Arabia, as described in other studies. $^{31-34}$ A meta-analysis found that psychotropic drugs (tricyclic antidepressants, antipsychotics, or both, but not selective serotonin reuptake inhibitors) are effective for PDS. ${ }^{35}$ In addition, other psychotropic drugs, psychotherapy, and experimental therapies (e.g., rifaximin) are not used. Other treatment options for dyspeptic patients include proton-pump inhibitors, prokinetics, and antibiotics against $H$. pylori according to the AGA and CAG guidelines, but not antidepressants or anti-anxiety drugs, as stepwise recommended. ${ }^{21,22}$ These recommendations apply to EPS, the most prevalent subtype across the country. The findings highlight the importance of not using a therapeutic designated for one disease subtype to treat another subtype, e.g., expecting prokinetics to resolve PDS or proton-pump inhibitors to treat PDS and the overlapping EPS-PDS variant. The prescription of antibiotics to eradicate $H$. pylori (test and treat strategy) as a first step in managing dyspepsia is helpful, given the high prevalence of $\mathrm{H}$. pylori infection throughout Saudi Arabia.

The $H$. pylori infection rate (25\%) may be lower than in other studies in SA, ranging from $31.8-82.2 \%^{15,16,19,36}$ due to differences in the age groups involved in the present study compared to the others. The great majority of the survey participants were aged 18-29 years of age. Furthermore, patients with FD symptoms were diagnosed according to the Rome IV diagnostic criteria, not the outdated definitions used in some older studies.

The prevalence of IBS among dyspeptic patients was 44\%. A higher prevalence was in overlapping variants, more than $2 / 3$ of dyspeptic patients, and lower (less than 1/5) in IBS with EPS. In population-based studies, the estimated prevalence of IBS among dyspeptic patients ranged between 13\% and $29 \%{ }^{37}$ This might be due to the use of different diagnostic criteria,

Among the dyspeptic participants, gastritis was the most common pathology with a frequency of $23 \%$, which was more or less similar to the results reported in Saudi Arabia and other Arab countries. ${ }^{16,17,38,39}$ Studies in the western world reported a higher prevalence of gastritis (62\%) among adults. $^{18}$ The difference in prevalence between SA and the western world may be due to alcohol, which is not widely con- sumed in SA.

A few independent factors appear to be associated with the Rome IV-based FD symptoms and subtypes, including co-occurrence of symptoms compatible with FH and IBS, physical QoL, and use of acid-suppressing medications. Similar to the present observations, a long-term follow-up study showed that a poor QoL was associated with $\mathrm{FD}^{40}$ and that the co-existence of other functional Gl diseases increases the chance of having FD symptoms, ${ }^{41,42}$ even though the underlying etiology remains unknown. Another independent factor was somatization, which was positively associated with the PDS and overlapping EPS-PDS variant subtypes, but not EPS, as reported in other studies. ${ }^{31,43-45}$

The main limitations of this study were its cross-sectional design and that the data were solely self-reported by the participants. Therefore, the diagnoses could not be confirmed by a clinical evaluation, nor could the endoscopy findings be verified despite the lack of diagnostic yield from performing an endoscopy study in the general population for FD. ${ }^{26,45}$ According to the joint ACG and CAG guidelines, because gastric cancer is rare in dyspeptic patients under 60 years of age, they do not routinely recommend upper Gl endoscopy as an initial management approach in dyspeptic patients, and the present population sample age was under 60 years of age and mostly younger ages. To address and avoid any potential selection bias, this study used a consistent and systematic methodological approach that was accessible throughout the country. The web-based survey generated new data on the epidemiology of FD subtypes, not overestimated because of outdated definitions of FD or underestimated due to the pitfalls of personal approaches (e.g., face-to-face and telephone interviews). ${ }^{14}$

In conclusion, this is the first survey-based study to assess the prevalence of FD symptoms according to the Rome IV diagnostic criteria in the general adult population of Saudi Arabia. An awareness of the epidemiology of FD symptoms, the subtypes, and their distinct therapeutic regimens, and the evolving Rome IV criteria will enable clinical practices to optimize the treatment of this prevalent condition. Improvements in clinical practice rely on the adherence to international guidelines in the diagnosis and management of dyspepsia, which is crucial for improving the QoL and avoiding unnecessary procedures and medications. This is particularly relevant to the PDS subtype for which most therapies are not 
sufficiently effective.

\section{REFERENCES}

1. Koduru P, Irani M, Quigley EMM. Definition, pathogenesis, and management of that cursed dyspepsia. Clin Gastroenterol Hepatol 2018;16:467-479.

2. Tack J, Talley NJ, Camilleri M, et al. Functional gastroduodenal disorders. Gastroenterology 2006;130:1466-1479.

3. Mearin F, Cucala M, Azpiroz F, Malagelada JR. The origin of symptoms on the brain-gut axis in functional dyspepsia. Gastroenterology 1991;101:999-1006.

4. Talley NJ, Hunt RH. What role does Helicobacter pylori play in dyspepsia and nonulcer dyspepsia? Arguments for and against $\mathrm{H}$. pylori being associated with dyspeptic symptoms. Gastro- enterology 1997;113 Suppl 6:S67-S77.

5. Tack J, Piessevaux H, Coulie B, Caenepeel P, Janssens J. Role of impaired gastric accommodation to a meal in functional dyspepsia. Gastroenterology 1998;115:1346-1352.

6. Walker MM, Talley NJ, Prabhakar M, et al. Duodenal mastocytosis, eosinophilia and intraepithelial lymphocytosis as possible disease markers in the irritable bowel syndrome and functional dyspepsia. Aliment Pharmacol Ther 2009;29:765-773.

7. Drossman DA, Creed FH, Olden KW, et al. Psychosocial aspects of the functional gastrointestinal disorders. Gut 1999;45 Suppl 2:II25-II30.

8. Vanheel H, Carbone F, Valvekens L, et al. Pathophysiological abnormalities in functional dyspepsia subgroups according to the Rome III criteria. Am J Gastroenterol 2017;112:132-140.

9. Hammer J. Identification of individuals with functional dyspepsia with a simple, minimally invasive test: a single center cohort study of the oral capsaicin test. Am J Gastroenterol 2018;113: 584-592.

10. Stanghellini V, Chan FK, Hasler WL, et al. Gastroduodenal disorders. Gastroenterology 2016;150:1380-1392.

11. Drossman DA, Hasler WL. Rome IV-functional GI disorders: disorders of gut-brain interaction. Gastroenterology 2016;150: 1257-1261.

12. Drossman DA. Functional gastrointestinal disorders: history, pathophysiology, clinical features, and Rome IV. Gastroenterology 2016;150:1262-1279.

13. Palsson OS, Whitehead WE, van Tilburg MAL, et al. Development and validation for Rome IV diagnostic questionnaire for adults. Gastroenterology 2016;150:1481-1491.

14. Ford AC, Marwaha A, Sood R, Moayyedi P. Global prevalence of, and risk factors for, uninvestigated dyspepsia: a meta-analysis. Gut 2015;64:1049-1057.

15. Alanazi BG, Alanazi FH, Albriek AZ, et al. The prevalence of Helicobacter pylori infection in patients with dyspepsia in the central rural region of Saudi Arabia. IAJPS 2019;6:1358-1364.

16. Akeel M, Elmakki E, Shehata A, et al. Prevalence and factors associated with H. pylori infection in Saudi patients with dyspepsia. Electron Physician 2018;10:7279-7286.

17. Masoodi I. The prevalence and risk factors of non-ulcer dyspepsia in the western region of Saudi Arabia: short form Leads dys- pepsia questionnaire revisited. Int J Med Sci Public Health 2018;7:915-921.

18. Ayoola AE, Ageely HM, Gadour MO, Pathak VP. Prevalence of Helicobacter pylori infection among patients with dyspepsia in South-Western Saudi Arabia. Saudi Med J 2004;25:1433-1438.

19. Morad NA, Ahmed ME, Al-Wabel A, et al. Helicobacter pylori associated dyspepsia in 208 patients from southern Saudi Arabia. Ann Saudi Med 1993;13:340-343.

20. Spiller RC, Humes DJ, Campbell E, et al. The patient health questionnaire 12 somatic symptom scale as a predictor of symptom severity and consulting behaviour in patients with irritable bowel syndrome and symptomatic diverticular disease. Aliment Pharmacol Ther 2010;32:811-820.

21. Moayyedi P, Lacy BE, Andrews CN, Enns RA, Howden CW, Vakil N. ACG and CAG clinical guideline: management of dyspepsia. Am J Gastroenterol 2017;112:988-1013.

22. Enck P, Azpiroz F, Boeckxstaens G, et al. Functional dyspepsia. Nat Rev Dis Primers 2017;3:17081.

23. Ware JE, Kosinski M, Dewey JE, et al. How to score and interpret single-item health status measures: a manual for users of the SF- $8^{\text {TM }}$ Health Survey. Lincoln: Quality Metric Incorporated, 2001.

24. Aziz I, Palsson OS, Törnblom H, Sperber AD, Whitehead WE, Simrén M. Epidemiology, clinical characteristics, and associations for symptom-based Rome IV functional dyspepsia in adults in the USA, Canada, and the UK: a cross-sectional population-based study. Lancet Gastroenterol Hepatol 2018;3: 252-262

25. Zagari RM, Law GR, Fuccio L, et al. Epidemiology of functional dyspepsia and subgroups in the Italian general population: an endoscopic study. Gastroenterology 2010;138:1302-1311.

26. Bernersen B, Johnsen R, Straume B. Non-ulcer dyspepsia and peptic ulcer: the distribution in a population and their relation to risk factors. Gut 1996;38:822-825.

27. Wang $A$, Liao X, Xiong $L$, et al. The clinical overlap between functional dyspepsia and irritable bowel syndrome based on Rome III criteria. BMC Gastroenterol 2008;8:43.

28. van Kerkhoven LA, Laheij RJ, Meineche-Schmidt V, Veldhuyzenvan Zanten SJ, de Wit NJ, Jansen JB. Functional dyspepsia: not all roads seem to lead to Rome. J Clin Gastroenterol 2009;43: 118-122.

29. Carbone F, Holvoet L, Tack J. Rome III functional dyspepsia subdivision in PDS and EPS: recognizing postprandial symptoms reduces overlap. Neurogastroenterol Motil 2015;27:1069-1074.

30. Pleyer C, Bittner H, Locke GR 3rd, et al. Overdiagnosis of gastro-esophageal reflux disease and underdiagnosis of functional dyspepsia in a USA community. Neurogastroenterol Motil 2014; 26:1163-1171.

31. Hsu YC, Liou JM, Liao SC, et al. Psychopathology and personality trait in subgroups of functional dyspepsia based on Rome III criteria. Am J Gastroenterol 2009;104:2534-2542.

32. Talley NJ, Locke GR, Saito YA, et al. Effect of amitriptyline and escitalopram on functional dyspepsia: a multicenter, randomized controlled study. Gastroenterology 2015;149:340-349.e2.

33. Lacy BE, Parkman HP, Camilleri M. Chronic nausea and vomiting: evaluation and treatment. Am J Gastroenterol 2018;113: 
647-659.

34. Herrick LM, Camilleri M, Schleck CD, Zinsmeister AR, Saito YA, Talley NJ. Effects of amitriptyline and escitalopram on sleep and mood in patients with functional dyspepsia. Clin Gastroenterol Hepatol 2018;16:401-406.e2.

35. Ford AC, Luthra P, Tack J, Boeckxstaens GE, Moayyedi P, Talley NJ. Efficacy of psychotropic drugs in functional dyspepsia: systematic review and meta-analysis. Gut 2017;66:411-420.

36. Akeel M, Shehata A, Elhafey A, et al. Helicobacter pylori vacA, cagA and iceA genotypes in dyspeptic patients from southwestern region, Saudi Arabia: distribution and association with clinical outcomes and histopathological changes. BMC Gastroenterol 2019;19:16.

37. Tan VP, Liu KS, Lam FY, Hung IF, Yuen MF, Leung WK. Randomised clinical trial: rifaximin versus placebo for the treatment of functional dyspepsia. Aliment Pharmacol Ther 2017;45:767-776.

38. Al-Karawi MA. Evaluation of gastro-esophageal reflux disease results in 40 patients. Saudi Med J 1992;13:407-411.

39. Wahass S, Khalil MS, AI Qurain AA, Yasawy MI. The impact of functional dyspepsia on health-related quality of life in Saudi patients. Saudi J Gastroenterol 2006;12:123-129.
40. Ford AC, Forman D, Bailey AG, Axon AT, Moayyedi P. Initial poor quality of life and new onset of dyspepsia: results from a longitudinal 10-year follow-up study. Gut 2007;56:321-327.

41. Ford AC, Marwaha A, Lim A, Moayyedi P. Systematic review and meta-analysis of the prevalence of irritable bowel syndrome in individuals with dyspepsia. Clin Gastroenterol Hepatol 2010;8: 401-409.

42. Locke GR 3rd, Zinsmeister AR, Fett SL, Melton $\sqcup$ 3rd, Talley NJ. Overlap of gastrointestinal symptom complexes in a US community. Neurogastroenterol Motil 2005;17:29-34.

43. Fang YJ, Liou JM, Chen CC, et al. Distinct aetiopathogenesis in subgroups of functional dyspepsia according to the Rome III criteria. Gut 2015;64:1517-1528.

44. Aro P, Talley NJ, Ronkainen J, et al. Anxiety is associated with uninvestigated and functional dyspepsia (Rome III criteria) in a Swedish population-based study. Gastroenterology 2009;137: 94-100.

45. Zagari RM, Law GR, Fuccio L, et al. Epidemiology of functional dyspepsia and subgroups in the Italian general population: an endoscopic study. Gastroenterology 2010;138:1302-1311. 